\title{
Essential Mechanical Properties of Structural Steels for Steel Reinforced Buildings in the Earthquake Sensitive Areas
}

\author{
M. A. Islam* \\ Materials and Metallurgical Engineering Department, Bangladesh University of Engineering and \\ Technology (BUET), Dhaka-1000, Bangladesh
}

Received 14 February 2011, accepted in final revised form 12 November 2011

\begin{abstract}
During earthquake, the ground along with its various natural and manmade structures experiences shaking of various intensities and frequencies depending on the nature of the earthquake. The loading activities caused by earthquakes on various structures are very much cyclic type, which is popularly known as fatigue loading. On the other hand, for modern high-rise buildings a large volume of steel bar is used to reinforce the concrete because of the pioneer role of steel bars embedded inside the concrete for safety of the buildings. In this study various mechanical properties of reinforcing steel bars that are essential to counter balance the earthquake effects have been identified first. At the same time these essential mechanical properties have been defined and studied for most commonly used reinforcing steel bars. For doing this, both the conventional and advanced structural steels were selected. The mechanical properties and fatigue behaviours of these steels have been presented and discussed in this paper.
\end{abstract}

Keywords: Earthquake; High-rise buildings; Reinforcing steel bars; Conventional structural steel; Advanced structural steel.

(c) 2012 JSR Publications. ISSN: 2070-0237 (Print); 2070-0245 (Online). All rights reserved.

doi:10.3329/jsr.v4i1.7069 J. Sci. Res. 4 (1), 51-63 (2012)

\section{Introduction}

Earthquakes cause the ground to shake violently in the form of wave thereby triggering the landslides, creating floods, causing the ground along with its various manmade or natural structures to heave and crack with subsequent destruction to life and property. For any structure to be earthquake resistant, the ductility of reinforcing materials used for the structure plays an important role [1-3], because earthquake causes deformation in the affected structures during its cyclic loading. Here it is to be mentioned that the qualities of compressive load bearing materials of the concrete such as cement, gravel, sand, etc. are also very important $[4,5]$. Now, let us define the term “ductility”. Ductility is the property,

\footnotetext{
*Corresponding author: aminulislam@mme.buet.ac.bd
} 
which allows the structure to undergo a large plastic deformation without significant loss of strength, which has been shown in Fig. 1(a). On the other hand, hysteretic energy is the energy dissipated by inelastic cyclic deformations and is given by the area within the loaddeformation curve, which is also known as hysteretic curve. The hysteresis curves of brittle and ductile materials are, respectively, shown in Figs. 1(b) and (c). High hysteretic energy (high toughness) of the reinforcing steel bars also increase the safety of the structural buildings. On this point of view, reinforcing steel bars must have high strength and high ductility.

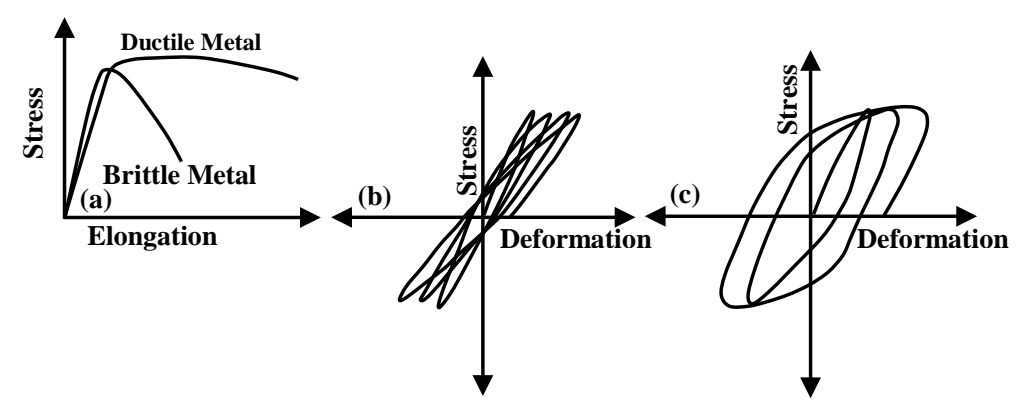

Fig. 1. (a) Stress-elongation curves of brittle and ductile materials, (b) and (c) are, respectively, hysteretic diagrams of brittle and ductile materials.

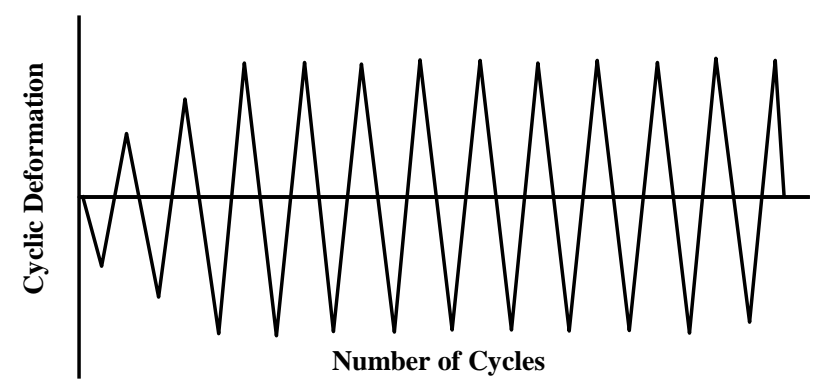

Fig. 2. Cyclic loading on structures caused by an earthquake.

Now, let us consider the loading effect caused by the earthquake. During earthquake, affected structures experience cyclic shaking or repeated loading. The pattern of repeated loading is shown in Fig. 2. For a particular earthquake, the frequency, intensity and number of vibration depend on the nature of the earthquake. However, it is well established that the loading effects caused by any earthquake are very similar to that of fatigue loading (loading-unloading-again loading and so on) effects. So, use of structural steels having higher strength but low fatigue resistance is not a good choice for earthquake resistant structural buildings $[6,7]$. Because of similar loading behaviours, both fatigue 
loading and shaking by earthquake induce cyclic loading actions as well as deformation in the structures [1]. Higher energy dissipation means better earthquake resistance and is controlled by both the level of ductility and strength of the material considered, which has also been mentioned. On the other hand, ductility also controls the bendability, which is another key property for the earthquake resistant reinforcing steel bar [8-11]. The aim of this paper is to discuss the loading behaviours of some commonly used reinforcing steel bars and also the essential mechanical properties that might improve the safety of the steel reinforced structures in the earthquake sensitive areas.

\section{Experimental Procedure}

\subsection{Materials}

For this research work, both the conventional and advanced structural steels (having carbon content around $0.2 \mathrm{wt} \%$ and carbon equivalent around 0.4-0.5 wt\%) were selected. For conventional steels, both low strength (hot rolled and air cooled; HR steel), high strength (hot rolled, air cooled and then 25\% cold rolled; HRC25) and hot rolled steels with high level of alloy, i.e. high level of carbon and manganese (HRHA) were used. On the other hand, in the case of advanced steel two types of steels (quenched and tempered, QT and transformation induced plasticity, TRIP steels) were selected. Details of chemical compositions of different steel are shown in Table 1.

Table 1. Chemical compositions of various structural steel used for this work.

\begin{tabular}{lccccc}
\hline Steel identification & \multicolumn{5}{c}{ Chemical compositions wt\% } \\
\hline & $\mathrm{C}$ & $\mathrm{Si}$ & $\mathrm{Mn}$ & $\mathrm{P}$ & $\mathrm{S}$ \\
Conventional HR & 0.21 & 0.60 & 1.20 & 0.040 & 0.035 \\
Conventional HRC25 & 0.21 & 0.60 & 1.20 & 0.040 & 0.035 \\
Conventional HRHA & 0.30 & 0.60 & 1.40 & 0.040 & 0.040 \\
QT Steel & 0.20 & 0.56 & 0.85 & 0.030 & 0.030 \\
TRIP Steel & 0.18 & 1.00 & 1.40 & 0.008 & 0.009 \\
\hline
\end{tabular}

\subsection{Microstructural characterization}

All steels selected for this study were polished and etched in nital following standard procedure and they were then photographed for microstructural analysis.

\subsection{Mechanical tests}

Considering all essential mechanical properties to counter balance the earthquake effects, initiative has been taken to investigate the tensile strength and ductility of various steel 
bars by tensile tests using Universal testing machine (UTM), whereas bendability has been assessed by standard bending tests on the same UTM. At the same time, fatigue life of the structural steels has been characterized by using a plane bending fatigue testing machine. A typical plane bending fatigue testing machine is shown in Fig. 3. In order to know the fatigue fracture behaviours, the fracture surfaces of both types of steels have been studied under scanning electron microscope.
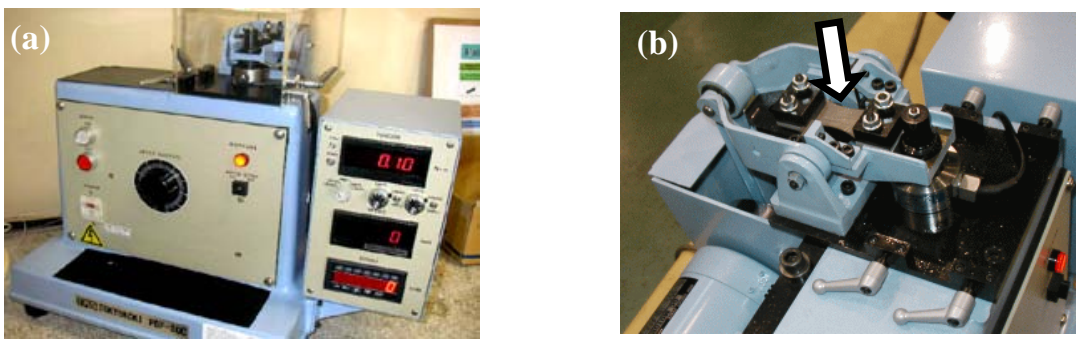

Fig. 3. (a) Plane bending fatigue testing machine and (b) specimen under test condition (marked by arrow).

\section{Results and Discussion}

Before discussing the experimental results, essential mechanical properties of seismic resistant steel bars will be mentioned. In this regard, various international bodies such as American Concrete Institute (ACI), American Society of Civil Engineers (ASCE), International Building Code (IBC), Europe Code (EC), European Convention for Constructional Steelworks (ECCS), etc. have given the technical basis and played a leading role for coordination and harmonization in designing steel reinforced concrete structures for seismic resistant building. The common suggestion from all bodies is that the steel reinforcing bars should possess adequate ductility and toughness with capacity to sustain cycles of deformation with high strains. As per these codes, the structural steel should have yield stress 400-500 MPa, whereas ultimate tensile strength must be at least 1.2 times of that of yield strength. The ductility level mostly depends on strength of earthquake. However, elongation higher than 14\% is widely suggested [12-13]. As higher strength reduces the tensile elongation, very high strength steel is not suggested to use.

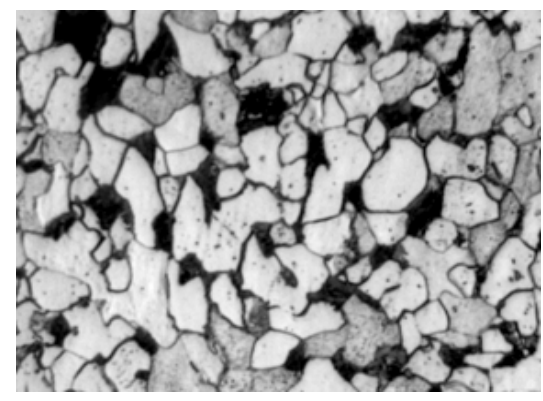

Fig. 4. Ferrite-pearlite structures of hot rolled steel.

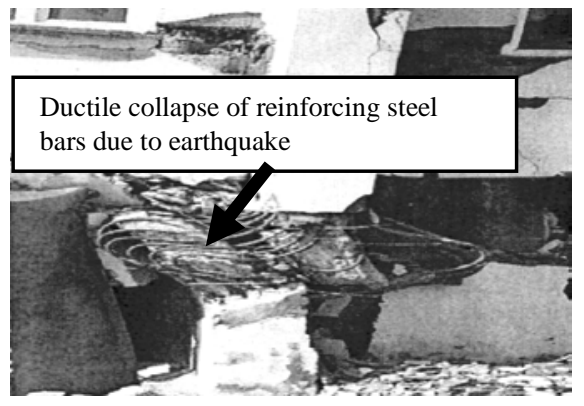

Fig. 5. Ductile collapse (marked by arrow) of reinforcing steel bars used in the column. 
For low strength conventional reinforcing structural steels, the HR steels are cooled naturally in the air after final rolling. So, the microstructure of this steel becomes to be composed of normalized ferrite-pearlite as shown in Fig. 4. Here it is important to mention that the white and black grains of the microstructure, respectively, are ferrite and pearlite, which are the main constituent phases of mild or structural steels. This type of steel usually exhibits a very high level of ductility. However, because of relatively low strength, it is not wise to use this type of steel in high-rise buildings. The reason behind this is that the use of low strength steel requires higher proportions of steel bars, which ultimately increases the overall weight of buildings. As a result, the reinforcing steel bars of the heavy weight structures might fail by means of ductile collapse during the time of earthquake as shown in Fig. 5.

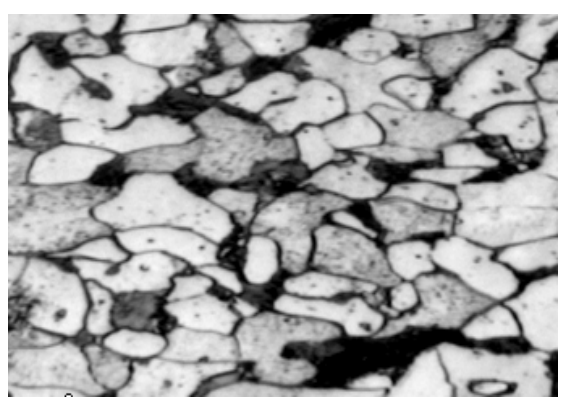

Fig. 6. Elongated ferrite-pearlite structures of cold rolled steel.

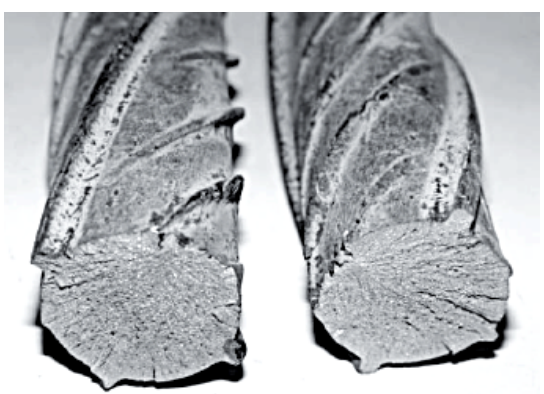

Fig. 7. Brittle type failure during bending test of a conventional high strength reinforcing steel bar.

In order to reduce the proportion of steel consumption, local steel producers are trying to increase the strength of the conventional hot rolled steel bars by adding more carbon and manganese or other alloying elements (HRHA steel). Here it is mentioned that high carbon and high manganese steel is also not good for structural application because of its relatively lower corrosion resistance and poor ductility/bendability [14, 15]. Sometimes the steel producers also roll the product below the insufficient hot rolling temperature or spray cold water over the finished product to achieve high tensile and yield strengths. Here it is very important to mention that any rolling below the hot rolling temperature increases the tensile strength of the steel because of unrecoverable deformation of the ferrite-pearlite grains. In this case, the equiaxed ferrite-pearlite grains (as shown in Fig. 4), become elongated in the direction of rolling (as shown in Fig. 6). These types of steel bars (HRC25) ultimately result poor ductility/bendability and fail in brittle manner during bend test. The brittle type fracture surface is shown in Fig. 7. Because of high strength of this type of conventional steel, the total steel consumption for a particular application might decrease. However, due to poor bendability, this type of structural steel decreases the earthquake resistance of the building. As a result, structures reinforced with this type of structural steel, in many cases, fail catastrophically (as shown in Fig. 8) during the time of 
earthquake of sufficiently high intensity and cause a huge damage to life and property. So, it is not wise to use this type of steel as reinforcing material.

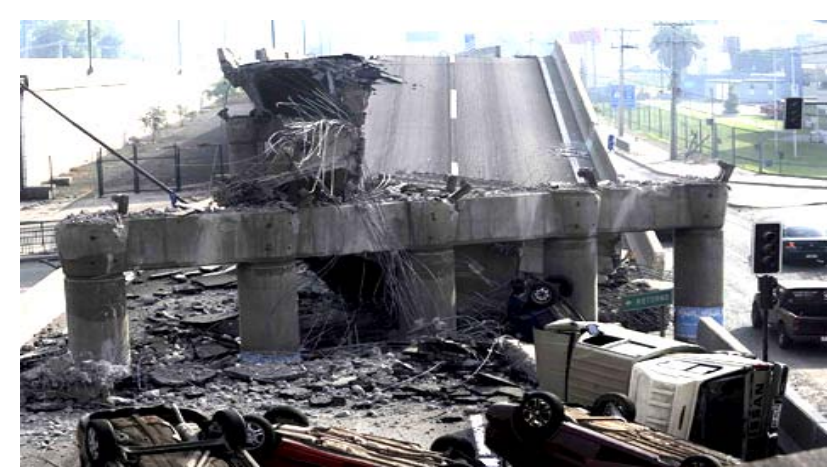

Fig. 8. Earthquake related catastrophic failures in structures reinforced with brittle steel bars.

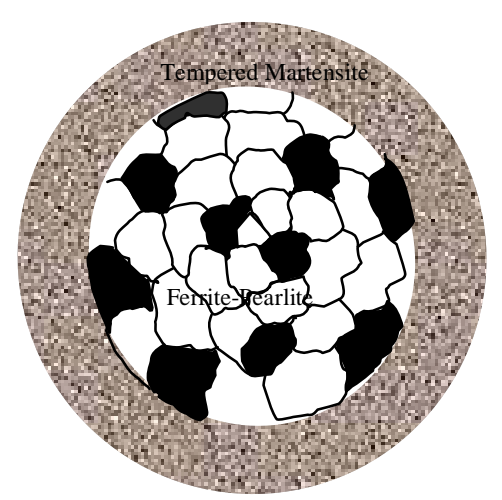

Fig. 9. Microstructures of the OT steel.

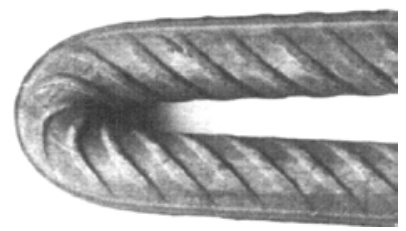

Fig. 10. After bending test of the QT steel.

Without deteriorating the essential mechanical properties of structural steels, there are various thermomechanical treatment options to produce steel bars. One of these options is the quenching and tempering (QT technique). For QT steel, after final pass of rolling, the hot rolled steel bars are quickly passed through a chamber with water flow from different directions. Finally, the dynamically quenched bar is naturally cooled in air on specially made cooling bed. So, the microstructure of outer layers of the bars become tempered martensite because of quick quenching action on outer surface layers and the inner core remains to be normal ferrite-pearlite. This type of microstructure is shown in Fig. 9. The 
outer tempered martensitic structures provide high strength and the ferrite-pearlite core ensures high ductility. Overall, the ductility and strength level of this type of steel is very favourable for structural applications and that the bendability of this steel becomes also very good. This type of steel does not fail after $180^{\circ}$ bending, which is clear from Fig. 10. The mechanical properties of these steels are also as per the suggestion of various building codes [12-13].

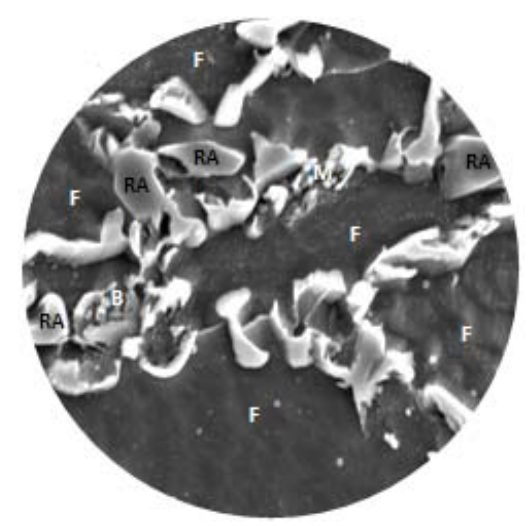

Fig. 11. Microstructures of transformation induced plasticity (TRIP) steel.

Another option of increasing the strength of the structural steel is by the combination of grain refinement and by retaining certain fraction of metastable austenite in the structures. From Hall-Petch relationship, it is well established that grain refining increases the strength of any material. On the other hand, during loading, metastable retained austenite (marked by RA in Fig. 11) transforms to high strength and more stable bainite (marked by B) phase. This austenite transformation to bainite also induces additional plasticity/ductility to the steel. As a result, this type of steel is usually termed as transformation induced plasticity or TRIP steel. The final structure of this steel becomes to be composed of several different phases like ferrite (marked by F), retained austenite (marked by RA), bainite (marked by B) and martensite (marked by M) of varying proportions. Microstructure of this type of steel is shown in Fig. 11. So, TRIP steel is occasionally named as multiphase high strength steel. The unique property of the TRIP steel is its very high strength along with its extra ordinary ductility, which is very essential for earthquake resistance buildings. The tensile properties of reinforcing steel bars so far discussed are presented in Table 2 for a comparative study. Although, the yield strength of this steel is beyond the range mentioned in the building codes, however, this steel might usher a new horizon in the field of steel reinforced concrete structures. The reasons behind this are its very high ultimate strength compared to its yield strength and attractive elongation (Table 2). 
Table 2. Tensile properties of various structural steels studied in this work.

\begin{tabular}{lccc}
\hline Steel Identification & Yield strength (MPa) & Tensile strength (MPa) & Elongation (\%) \\
\hline Conventional HR & 275 & 400 & $>25$ \\
Conventional HRC25 & 530 & 540 & $\sim 8$ \\
Conventional HRHA & 510 & 620 & $\sim 12-14$ \\
QT Steel & 520 & 650 & $\sim 20$ \\
TRIP Steel & 550 & 780 & $\sim 35$ \\
\hline
\end{tabular}

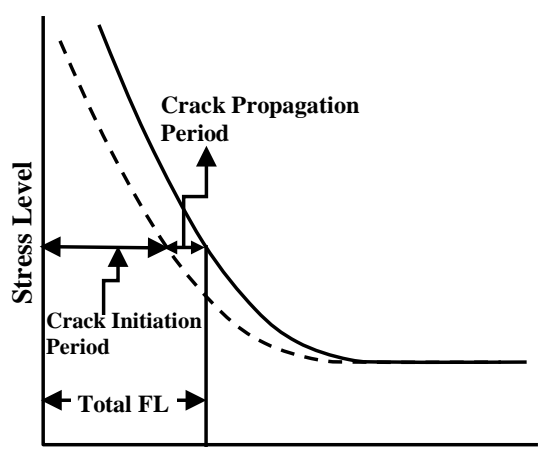

Fatigue Life (FL)

Fig. 12. Effect of applied cyclic stress level on the total fatigue life of a component.

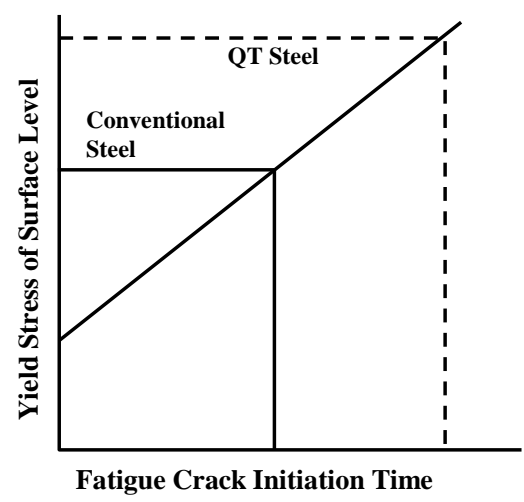

Fig. 13. Effect of surface yield strength on fatigue crack initiation time of a component.

In the earlier section, it has been recognized that longer fatigue life of the reinforcing steel bars is very essential to counter balance the earthquake induced cyclic loading effect. Better fatigue resistance of materials used for making any engineering component provides better longevity of the product. It has been found that more than $90 \%$ engineering components are failed by means of fatigue $[6,16]$. Extensive researches on fatigue behaviours of materials established that the total fatigue life of a component is composed of two different regimes, namely crack initiation period and crack propagation period as shown in Fig. 12. In general, total fatigue life is dominated by crack initiation period, which is also clear from this figure. If it is possible to increase the fatigue initiation period longer then higher will be the total fatigue life. It is also proved that higher yield strength of material means longer crack nucleation period, which is clear from Fig. 13. Here it is important to mention that, during cyclic loading, fatigue crack usually initiates from the surface having highest level of effective tensile stress. So, better surface finish as well as the yield strength of steel surface plays important role to control the fatigue crack initiation period and also the total fatigue life. In this case, QT steel shows unique combination of surface finish and high surface strength. QT bars are usually 
made by 16-18 rolling passes, whereas it is about 8-10 for conventional hot rolled steel bar production. Because of higher number of passes, surfaces of the QT steel bars become relatively smoother. It has also been mentioned that after final pass of rolling, QT steel bars are quenched by controlled water flow. Due to this controlled water flow the material at the surface layer is only selectively quenched and subsequently tempered resulting tempered martensitic structure, which is very strong. Both smooth surface and higher level of surface strength of QT steel bars retard the crack initiation period. So, QT steel bars show unparallel fatigue life compared to any other conventional structural steel having similar chemical compositions and/or average strength level.
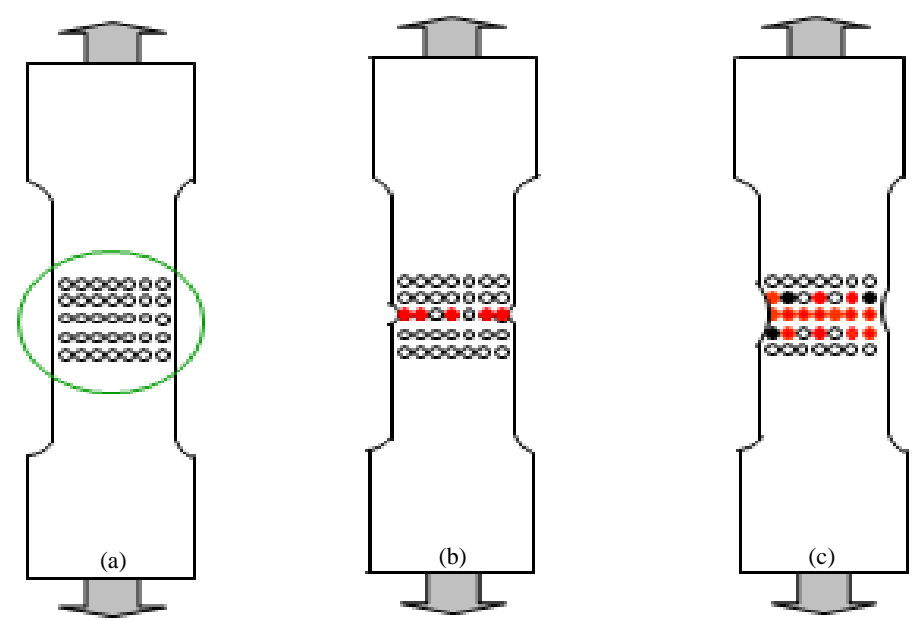

Fig. 14. Transformation of retained austenite (empty or filled black circles) to bainite (red circles) under tensile loading of TRIP steel (a) initial stage, (b) just after necking and (c) after a significant amount of necking.

It has been mentioned that thermomechanically treated QT steel has a very high earthquake resistance. In terms of earthquake resistance, TRIP steel is one step ahead compared to that of QT group. The reasons of this superiority of TRIP steel over QT will be discussed now. QT steel is finally quenched in water dynamically, which results tempered martensite. This tempered martensite is not completely residual stress free. So, having similar chemical compositions, corrosion resistance of TRIP steel is better than the QT steel. Improper quenching and tempering might cause brittle zone on the surface areas of the QT steel. In such case, if there is any surface imperfection, QT steel might behave as a notched or brittle material and subsequently result lower fatigue limit because of stress concentration effect. But TRIP steel, from surface to core, has uniform microstructures with higher ductility level. Moreover, for conventional or QT steel total applied load is absorbed by elastic and plastic deformations. As a result, continuously, dislocation pile-up causes easy and early necking with subsequent failures in these steels. 

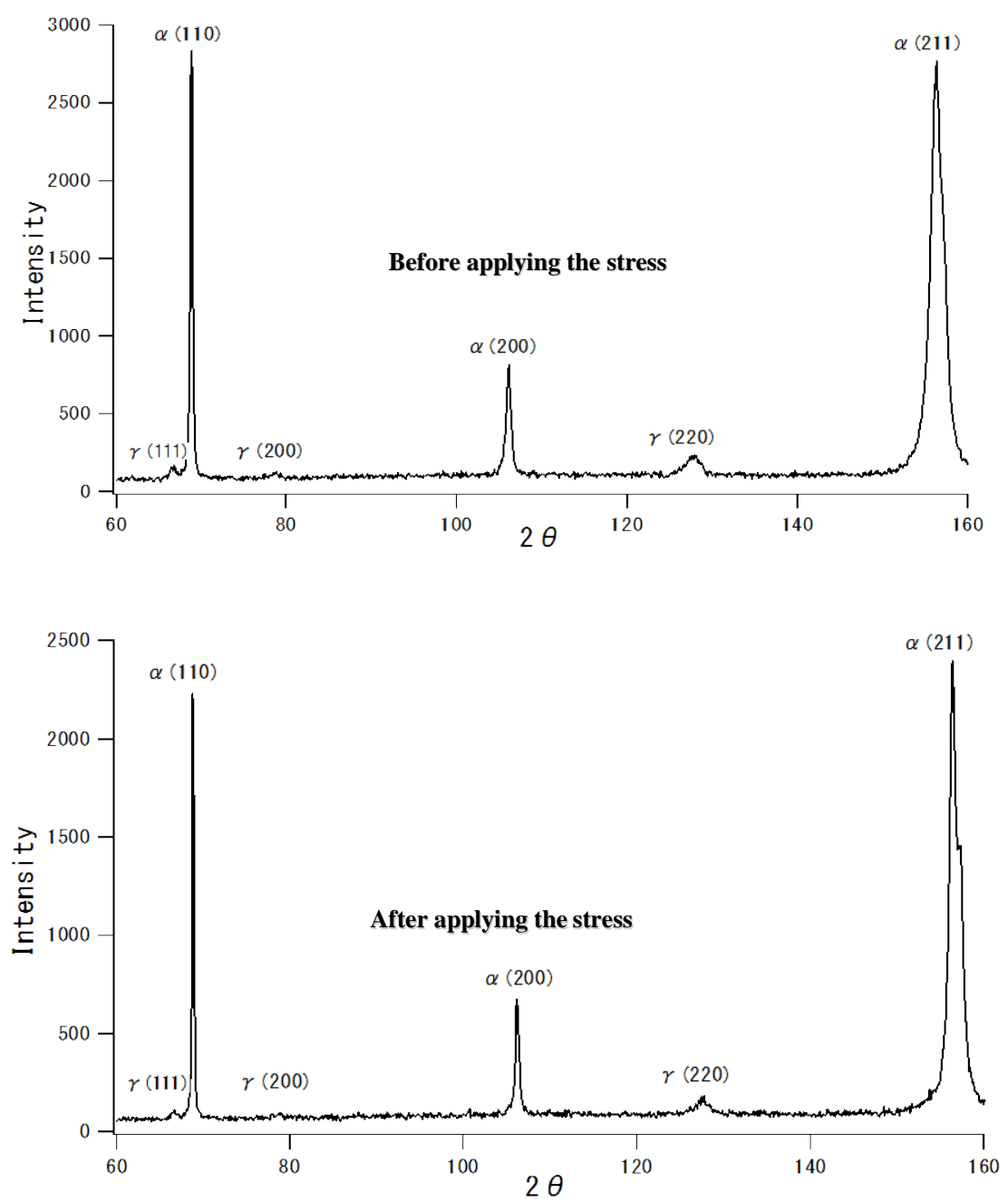

Fig. 15. XRD spectra showing the retained austenite transformation in TRIP steel before and after the application of stress.

On the other hand, TRIP steel is not very soft like conventional carbon steel or very hard like tempered martensite of surface layer of QT steel. As a result, total elongation related to elastic and inelastic deformation of TRIP steel is expected to be of moderate type. In the case of TRIP steel, another source of elongation is due to its strain-induced plasticity. During monotonic or cyclic loading (Fig. 14), when the applied load causes effective stress beyond the yield strength of any zone of the TRIP steel, then retained austenite in this steel starts to transform, which is clear from XRD spectra (Fig. 15).

This transformation of austenite ( $\gamma 200$ and 220 peaks) to bainite/martensite $(\alpha 110,200$ and 211 peaks) is an endothermic process, which needs some external energy. If the 
earthquake related strain causes sufficient stress on the TRIP steel bars, then retained austenite is transformed to bainite by absorbing fraction of shock energy created by the earthquake. As a result, effective shock energy to damage any structure will be somewhat lower. This type of behaviour of TRIP steel provides double guard for the buildings. The double guards are: i. by absorbing certain fraction of earthquake related stress due to transformation of RA to bainite, which will ultimately reduce the effective intensity of earthquake and ii. transformation of austenite to bainite strengthens the steel [17-19], because bainite phase is usually stronger than that of austenite phase. Altogether, the fatigue property of TRIP steel is really excellent. As a result, TRIP type structural steel shows better fatigue life, which is many times higher than that of the conventional steel having similar level of tensile strength. From Fig. 16 it is clear that TRIP steel provides approximately ten times of fatigue life compared to that of conventional steel and that the fatigue limit of the TRIP steel is also significantly higher than that of the conventional steel considered. However, in the present case, no significant difference in the fatigue fracture morphologies of conventional and TRIP steel was noticed. In both cases transgranular type fracture surfaces (Fig. 17) have been observed.

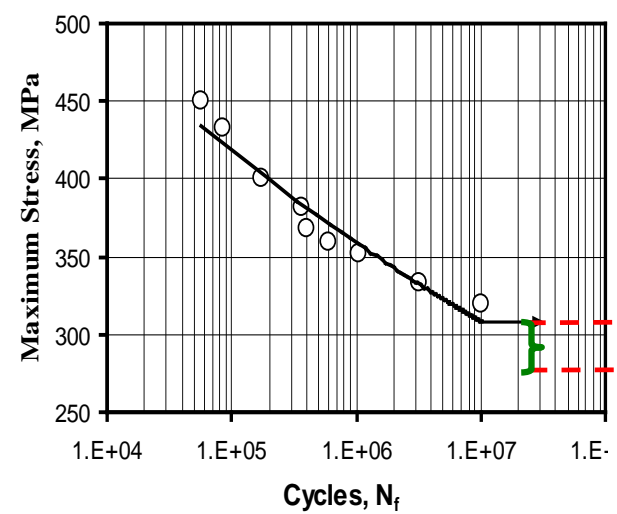

TRIP Steel

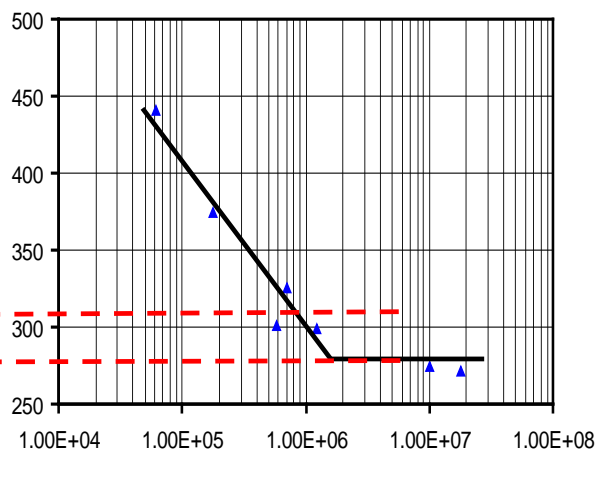

Conventional Steel

Fig. 16. Comparison of fatigue lives of TRIP and conventional structural steels of similar level of tensile strength.
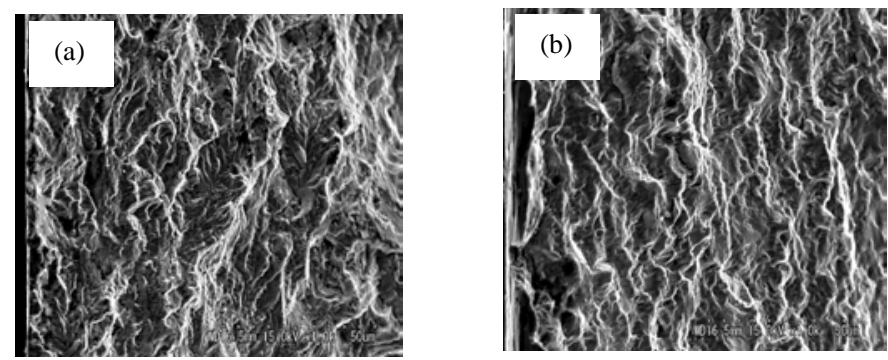

Fig. 17. Comparison of fatigue fracture morphologies of (a) HRC25 and (b) TRIP steels of similar yield strength levels. 
So far there is no technology or mechanism to stop or delay the occurrence of earthquake. However, modern technology is helping us to produce various heavy duty and high performance materials for different applications. So, we should be very careful and sincere to select right materials for right applications. At the same time, if we utilize our know-how to achieve perfect designs depending on situation, obviously we will be capable to reduce the degree of damage during earthquake. In this respect, if we try to look the worldwide scenario it would be possible to cite many examples of various degrees of earthquake related damages even though the intensities of the earthquakes were very similar. Haiti earthquake (intensity scale 7.0) that took place in January 2010 severely damaged almost all structures over there and around two hundred thirty thousand people were died. However, more powerful Chili earthquake (scale 8.8) that took place in February, 2010 caused a significantly lower damage to buildings and lives. On the other hand another earthquake of similar intensity took place in Kobe, Japan in January, 1995. In Kobe city, most of the buildings are high-rise. Compared to short buildings, high-rise buildings are more vulnerable to damage. However, in Kobe city lots of earthquake affected buildings were found to remain standing (Fig. 18c), which allowed the residents to go out from the buildings and save their lives. This is because of the utilization of perfect materials and perfect designs for the buildings. Photographs of some damaged buildings are represented to show a comparison of the degree of damages caused by those three different earthquakes in three different countries in Fig. 18.
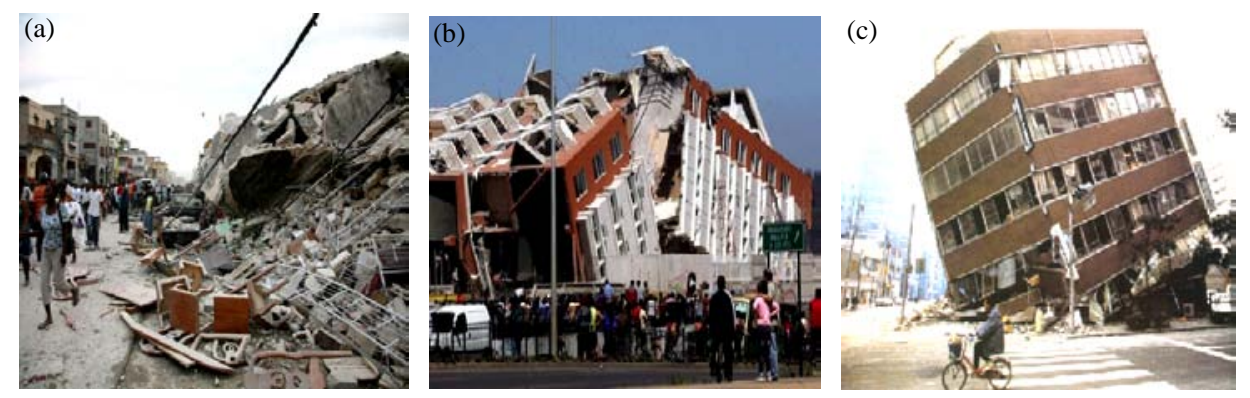

Fig. 18. Photographs showing the degree of building damages (a) Haiti, (b) Chili and (c) Kobe earthquakes.

\section{Final Remarks}

Reinforcing steel bars play the vital role for the safety of the structural buildings. In the case of earthquake resistant structural buildings, a large amount of reinforcing steel bars is used. If conventional low strength hot rolled steel bars are used, the steel consumption will be rather high, which is not good from earthquake point of view. Because, heavy consumption of steel bars makes the structure to be relatively bulky and that earthquake related damage is proportional to the overall weight of the structure. High strength 
conventional steel bars made from secondary induction melting practice in Bangladesh are also not good because of their low ductility and poor bendability levels. In this situation, use of thermomechanically treated high strength and high ductility steel bars might provide necessary solution for increasing the safety of the structural buildings against earthquake related damages. Use of good quality QT type thermomechanically produced steel bars will obviously reduce the overall weight of the structure and risk of earthquake related damage. In this regard, TRIP type thermomechanically treated steels provide extra benefit as it absorbs a certain fraction of the earthquake energy because of endothermic deformation of metastable retained austenite to high strength and more stable bainite phases. Finally, it is concluded that use of perfect materials with perfect design we can save many lives and lot of valuable properties.

\section{References}

1. J. G. Sing, N. Bandyopadhyay, and O. N. Mohanty, Practical Failure Analysis, 1 (5), 53 (2001). http://www.ingentaconnect.com/content/klu/pfa/2001/00000001/00000005/art00012

2. S. Otani, J. Adv. Concrete Tech.. 2 (1), 3 (2004).

3. Australian/New Zealand Standard for Steel Reinforcing Materials, AS/NZS 4671 (2001). http://www.saiglobal.com/PDFTemp/Previews/OSH/as/as4000/4600/4671.pdf

4. M. A. Saleem and M. Ashraf, Pak. J. Eng. Appl. Sci. 2, 59 (2008).

5. Commonwealth Report, Commonwealth Hazard Centre News Letter 4 (3), 1 (2001).

6. T. L. Anderson, Fracture Mechanics Fundamentals and Applications, $2^{\text {nd }}$ Edition, (CRC Press, New York, 1995). http://www.crcpress.com/product/isbn/9780849316562

7. G. E. Dieter, Mechanical Metallurgy, SI Metric Edition (McGraw-Hill, New York, 1988).

8. M. Takashi, O. Kawano, T. Hayashida, R. Okamoto, and H. Taniguchi, Nippon Steel Technical Report 88, 1 (2003). http://www.nsc.co.jp/en/tech/report/pdf/n8803.pdf

9. D. Beynon, T.B. Jones, and G. Fourlaris, Mat. Sci. Techn. 21 (1), 103 (2005).

10. Y. Tomota, H. Tokuda, Y. Adachi, M. Wakita, , N. Minakawa, A. Moriai and Y. Morii, 52, 5737 (2004).

11. K. Hulka, J. Mat. Sci. Forum 473, 91 (2005).

12. G. Jha, A. K. Sinha, N. Bandyopadhyay, and O. N. Mohanty, J. Practical Failure Analysis 5, 53 (2001). http://dx.doi.org/10.1361/152981501770352590

13. Seismic Design of Reinforced Concrete Special Moment Frames: A Guide for Practicing Engineers, National Institute of Standards and Technology. http://www.nehrp.gov/pdf/nistgcr8-917-1.pdf

14. B. K. Panigrahi, S. Srikanth, and G. Sahoo, Journal. Mat. Eng. Perform, ASM International 18, 1102 (2009).

15. R. Manoharan, P. Jayabalan, and K. Palanisamy, ICCBT, 239 (2008).

16. R. W. Hertzberg, Deformation and Fracture Mechanics of Engineering Materials John Wiley \& Sons Inc., New Jersey (1995).

17. M. A. Islam, S. Chain, and Y. Tomota, J. Mat. Eng. Performance, ASM International, 16 (2), 248 (2007).

18 .M. A. Islam, BSME-ASME Conference, Held in Dhaka (2008) pp. 245-251.

19. M. A. Islam and Y. Tomota, Int. J. Mater. Res. (formerly Metallkunde, German) 97 (11), 1559 (2006). 